\title{
Abnormal expression of acid glycosidases in seminal plasma and spermatozoa from infertile men with varicocele
}

\author{
J. J. Corrales ${ }^{1}$, R. M. Burgo ${ }^{1}$, P. Galindo ${ }^{3}$, I. Muñoz-Barroso ${ }^{2}$, \\ J. M. Miralles ${ }^{1}$ and E. Villar ${ }^{2}$ \\ ${ }^{1}$ Departamento de Medicina, Servicio de Endocrinología, ${ }^{2}$ Departamento de Bioquímica y \\ Biología Molecular and ${ }^{3}$ Departamento de Estadística, Universidad de Salamanca, \\ Salamanca, Spain
}

The activities of acid $\beta$-glucuronidase, $\alpha$-mannosidase, $\alpha$-glucosidase, $\alpha$-galactosidase, $\beta$-galactosidase and $\beta$ - $N$ acetylglucosaminidase were analysed in seminal plasma and spermatozoa from 26 infertile men with varicocele and from 36 men of normal fertility. Semen samples from ten men with non-obstructive azoospermia were used as control specimens that contained the other components of semen. Spermatozoa were solubilized by both physical (homogenization) and chemical (Triton-X100) methods to obtain the soluble and non-soluble fractions. The activities of several glycosidases measured both in seminal plasma and spermatozoa were directly correlated with the numbers of spermatozoa and sperm motility, confirming previous studies. As some infertile patients with varicocele have normal semen parameters, whereas others have low numbers of spermatozoa and low sperm motility, the varicocele patients were prospectively divided into two groups: one $(n=15)$ with normal spermiograms and the other $(n=11)$ with abnormal spermiograms. The activities (expressed in $\mathrm{mU} \mathrm{ml}^{-1}$ ) of $\alpha$-mannosidase, $\beta$-galactosidase and $\beta$ - $N$-acetylglucosaminidase in seminal plasma of normozoospermic infertile patients with varicocele were significantly higher than those of fertile controls, but not when expressed in $U$ per $10^{8}$ spermatozoa. The activities of $\beta$-glucuronidase, $\alpha$-mannosidase, $\beta$-galactosidase and $\beta$ - $N$-acetylglucosaminidase in seminal plasma when expressed in $U$ per $10^{8}$ spermatozoa in varicocele patients with abnormal spermiograms were significantly higher than in those of men of normal fertility. The activity of $\alpha$ mannosidase in the soluble fraction of sperm homogenates, expressed as $\mathrm{U}$ per $10^{8}$ spermatozoa, was significantly higher in infertile patients with varicocele and abnormal spermiograms than in controls. In the non-soluble fraction of spermatozoa from infertile patients with varicocele, there was an increase in the expression of $\beta$-galactosidase and $\beta$ - $N$-acetylglucosaminidase activities compared with the fraction of spermatozoa from fertile subjects. In summary, infertile patients with varicocele displayed an overexpression of acid $\alpha$-mannosidase, $\beta$-galactosidase and $\beta-N$ acetylglucosaminidase activities in seminal plasma and spermatozoa that may be associated with functional defects in spermatozoa as these glycosidases play an important role in mammalian fertilization.

\section{Introduction}

Varicocele is common in infertile men and has a prevalence of $25-40 \%$ in patients classified as having idiopathic infertility (Braunstein, 1997). To date, spermiogram abnormalities have been demonstrated in varicocele patients, but impairment of the fertility potential has not been reported in these patients. The exact reasons why these patients are infertile is unknown (De Kretser and Baker, 1999).

Increasing evidence indicates a role for sperm glycosidases in mammalian fertilization. Thus, $\alpha$-mannosidase has been associated with the binding of spermatozoa to eggs (Cornwall et al., 1991); $\beta$-galactosidase has been implicated in sperm maturation during epididymal transit (Hall and Killian, 1987); and $\beta$ - $N$-acetylglucosaminidase has been

Email: corrales@usal.es shown to play a role in the penetration of egg coats (Miller et al., 1993; Takada et al., 1994). Spiessens et al. (1998) reported that the activity of $\alpha$-glucosidase in human seminal plasma can predict the outcome of intrauterine insemination. Preliminary studies have been conducted to analyse $\alpha$-glucosidase, a marker of epididymal function (Cooper et al., 1988), in the seminal plasma of patients with varicocele (Tremblay et al., 1982; Cooper et al., 1988), but other glycosidases or sperm acid glycosidases have not been studied in these patients. As the evaluation of enzymatic activity in spermatozoa has been considered a prerequisite for the appropriate diagnosis of functional defects in human spermatozoa (Schill et al., 1988), the aim of the present study was to determine whether acid glycosidase activities were altered in the seminal plasma and spermatozoa of infertile patients with varicocele. The content of several glycosidases in both the extracellular and intracellular seminal fractions of infertile patients with varicocele were 
analysed and compared with those obtained in a population of control men of normal fertility.

\section{Materials and Methods}

\section{Patients}

Semen samples were obtained by masturbation after a 4 day period of sexual abstinence from 36 healthy men (aged $33 \pm 5$ years) in whom fertility had been demonstrated in the previous 2 years and from 26 unselected and consecutive patients (aged $31 \pm 4$ years) consulting for primary infertility in which varicocele was present. Of these patients, 15 had normal spermiograms and 11 had abnormalities in one or more of the cytological semen parameters. The duration of infertility was $1.8 \pm 0.9$ years in the normozoospermic patients with varicocele and $2.6 \pm 1.6$ years in patients with abnormal semen parameters. In addition, ten patients with non-obstructive azoospermia were studied as negative controls due to the absence of spermatozoa in their spermiograms but the presence of the other components of semen. Varicocele was detected by physical examination and confirmed by Doppler ultrasonography of the spermatic cord. These patients were studied thoroughly, to exclude the presence of semen infection (bacterial culture), abnormalities in hormonal parameters in serum (including $\mathbf{L H}$, $\mathrm{FSH}$, total testosterone, prolactin and oestradiol measurements), iatrogenic causes or acquired testicular injury (traumatism, orchitis, torsion), and abnormalities in anti-sperm antibodies. Azoospermia was diagnosed when three semen samples contained no spermatozoa under microscopic examination of the sediment after centrifugation. The origin of azoospermia was identified by fine needle biopsy of testes that showed cytological changes, such as spermatogenic arrest, Sertoli cells only or hypospermatogenesis patterns. Karyotype analyses were normal in the ten azoospermic patients.

The techniques used for hormonal measurements and testicular biopsy have been described in detail (García Díez et al., 1983; Corrales et al., 1990; Santiago et al., 1997). Sperm vitality was evaluated by a staining technique using eosin-nigrosin (García Díez et al., 1991). Semen analyses were carried out by the same examiner and according to the procedure recommended by WHO (1999).

\section{Collection and preparation of semen samples}

Semen samples were collected in a sterile container and analysed within $1 \mathrm{~h}$ after ejaculation. The unprocessed semen was ultracentifuged at $62000 \mathrm{~g}$ for $20 \mathrm{~min}$ in a Beckman L8-70 ultracentrifuge (Beckman Instruments, Palo Alto, CA) at $4^{\circ} \mathrm{C}$. The supernatant was free of spermatozoa (confirmed by microscopy) and was referred to as seminal plasma. The pellet was also examined using microscopy and was shown to contain intact spermatozoa. The pellet was washed with isotonic saline and centrifuged at $800 \mathrm{~g}$ for $15 \mathrm{~min}$ in a Beckman TJ6 centrifuge (Beckman Instruments) at room temperature and this fraction was referred to as the 'pellet wash'. The pellet was solubilized by physical and chemical treatment with $1 \mathrm{ml}$ of $2 \%(\mathrm{v} / \mathrm{v})$ Triton-X100 (Sigma Chemical Co., St Louis, MO), followed

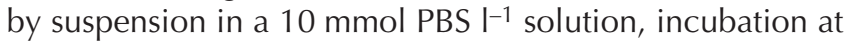
$37^{\circ} \mathrm{C}$ for $5 \mathrm{~min}$ and homogenization with a Polytron set at position five through three strokes of $10 \mathrm{~s}$ each. This homogenate was ultracentrifuged at $118000 \mathrm{~g}$ for $60 \mathrm{~min}$ at $4^{\circ} \mathrm{C}$. The supernatant was removed by aspiration and designated as the soluble fraction and the pellet as the nonsoluble fraction. From all these samples (whole unprocessed semen, seminal plasma, pellet wash, soluble and non-soluble fractions) two aliquots were obtained for duplicate measurements of enzymatic activities in each fraction. Mechanical disruption alone does not completely solubilize the enzymatic content of spermatozoa (Lessley and Garner, 1983) and, therefore, the detergent TritonX100, which induces complete extraction of the enzymes located within the spermatozoa, was used to complete the process (Lessley and Garner, 1983).

The study design was approved by the Ethics Committee for Clinical Research of the Hospital Universitario of Salamanca. Each participant gave informed consent before participating in the study.

\section{Enzyme assays}

The activities of $\beta$-glucuronidase, $\alpha$-mannosidase, $\alpha$-glucosidase, $\alpha$-galactosidase, $\beta$-galactosidase and $\beta$ - $N$ acetylglucosaminidase were measured by spectrofluorometric determination of one of the reaction products, 4-methyllumbelliferone, released enzymatically from each of the six 4-methyllumbelliferyl glycosides used as substrate, according to the method of Warner and O'Brien (1979) and modified by Miralles et al. (1982). The reaction mixture contained $50 \mu \mathrm{l}$ of $0.1 \mathrm{~mol}$ sodium citrate buffer $\mathrm{I}^{-1}, \mathrm{pH} 4.5,50 \mu \mathrm{l}$ 4-methyllumbelliferylglycoside ( $2 \mathrm{mmol} \mathrm{I}^{-1}$ for $\beta$-glucuronidase, $\alpha$-mannosidase and $\beta$ - $N$ acetylglucosaminidase, $1 \mathrm{mmol} \mathrm{I}^{-1}$ for $\alpha$-glucosidase and $\alpha$-galactosidase, and $0.5 \mathrm{mmol} \mathrm{I}^{-1}$ for $\beta$-galactosidase) and $25 \mu \mathrm{l}$ of the corresponding seminal fraction. The reaction mixture was incubated for $15 \mathrm{~min}$ at $37^{\circ} \mathrm{C}$ and the reaction was stopped by the addition of $2 \mathrm{ml}$ of $0.2 \mathrm{~mol}$ glycine- $\mathrm{NaOH}$ buffer $\mathrm{I}^{-1}(\mathrm{pH}$ 10.4). The fluorescence of the 4-methyllumbelliferone that was released was measured on a Hitachi F 4010 spectrofluorometer (Hitachi, Tokyo) at $365 \mathrm{~nm}$ for excitation and $450 \mathrm{~nm}$ for emission. In all measurements, blank substrates and blank samples were used, and all determinations were made in duplicate. One unit of enzyme activity was defined as the amount of enzyme required to release $1 \mu \mathrm{mol} 4$-methyllumbelliferone $\mathrm{min}^{-1}$ under the assay conditions. Other details of the methods, including intra-assay and interassay coefficients of variation for glycosidase activities, have been described by Corrales et al. (2000). Glycosidase activities are expressed in $\mathrm{mU} \mathrm{ml}^{-1}$ (in seminal plasma) or in $U$ per $10^{8}$ spermatozoa (in seminal plasma and spermatozoa) to enable a comparison of spermatozoa of different qualities. 
Table 1. Semen parameters in fertile control, varicocele and azoospermic men

\begin{tabular}{lcccc}
\hline Semen parameter & $\begin{array}{c}\text { Fertile controls } \\
(n=36)\end{array}$ & $\begin{array}{c}\text { Varicocele (NS) } \\
(n=15)\end{array}$ & $\begin{array}{c}\text { Varicocele (PS) } \\
(n=11)\end{array}$ & $\begin{array}{c}\text { Azoospermic } \\
(n=10)\end{array}$ \\
\hline Volume $(\mathrm{ml})$ & $4.1 \pm 2.2$ & $4.3 \pm 1.4$ & $4.3 \pm 2.6$ & $\begin{array}{c}2.6 \pm 1.8^{*} \\
(2)^{*}\end{array}$ \\
Number of spermatozoa & $114 \pm 69$ & $142 \pm 68$ & $50 \pm 32^{* *}$ & - \\
$\left(10^{6} \mathrm{ml}^{-1}\right)$ & $(109)$ & $(136)$ & $(47)^{* *}$ & - \\
Normal spermatozoa (\%) & $60 \pm 12$ & $59 \pm 16$ & $47 \pm 16^{* *}$ & $(50)^{* *}$ \\
Sperm motility grade & $(65)$ & $(63)$ & $33 \pm 11^{* *}$ & - \\
$3+2(\%)$ & $52 \pm 11$ & $55 \pm 7$ & $(40)^{* *}$ & - \\
Sperm motility grade 3 $(\%)$ & $(55)$ & $(50)$ & $15 \pm 7^{* *}$ & $(20)^{* *}$ \\
Necrozoospermia (\%) & $(32 \pm 11$ & $34 \pm 7$ & $24 \pm 13^{* *}$ & - \\
& $15 \pm 6$ & $17 \pm 6$ & $(18)^{* *}$ & \\
\hline
\end{tabular}

Results are expressed as means $\pm \mathrm{SD}$ and as medians (in parentheses).

${ }^{*} P<0.05,{ }^{* *} P<0.01$ versus fertile controls.

NS: normal spermiograms; PS: pathological spermiograms.

\section{Statistical analysis}

Data were analysed using the Instat statistical software GraphPad Program (San Diego, CA). The hormonal, spermiogram and enzymatic activities of the different groups were compared using the non-parametric MannWhitney $U$ test after analysis of the distribution of the variables. When the distribution of variables was normal, the Student's $t$ test was used. Relationships between semen parameters and glycosidase activities were determined using the Spearman's correlation coefficient. Results were considered significant at $P<0.05$. Values are expressed as means \pm SD and medians.

\section{Results}

The seminal parameters of varicocele patients with normal spermiograms were similar to those of the fertile controls as revealed by cytology, whereas in varicocele patients with abnormal spermiograms there was a significantly lower number of spermatozoa, of morphologically normal spermatozoa and sperm motility (grades $3+2$ and grade 3 ) and a significantly higher rate of necrozoospermia (Table 1). The basal serum concentrations of $\mathrm{LH}, \mathrm{FSH}$, testosterone, prolactin and oestradiol in fertile controls and in patients with varicocele were normal and not significantly different (data not shown). Azoospermic patients had higher concentrations of $\mathrm{LH}\left(9.4 \pm 7.3\right.$ versus $\left.3.2 \pm 2.2 \mathrm{miu} \mathrm{ml}^{-1}, P<0.01\right)$ and $\mathrm{FSH}\left(24.9 \pm 13.3\right.$ versus $\left.4.5 \pm 2.3 \mathrm{miu} \mathrm{ml}^{-1}, P<0.01\right)$ than did the controls. The circulating concentrations of the other hormones measured in the azoospermic patients were similar to those of the controls.

Several glycosidases measured in the seminal plasma and spermatozoa from men of normal fertility, infertile men with varicocele and azoospermic patients were clearly correlated with the number of spermatozoa and sperm motility (Table 2). No relationships were found with respect to sperm morphology. The inclusion of azoospermic patients to calculate the correlations in the whole group of patients studied may have introduced some bias in the results. However, in a previous study of a larger group of subjects $(n=117)$, excluding azoospermic patients, significant positive relationships were shown between acid glycosidase activities measured in seminal plasma and sperm homogenates with respect to number of spermatozoa and sperm motility (Burgo et al., 2000).

A very high correlation was found between the glycosidase activities measured in whole unprocessed semen and seminal plasma $(r>0.900)$; therefore, only the activities measured in seminal plasma are presented (Table 3). In varicocele patients with normal spermiograms, a significant increase in the activities (expressed as $\mathrm{mU}$ $\mathrm{ml}^{-1}$ ) of $\alpha$-mannosidase, $\beta$-galactosidase and $\beta$ - $N$ acetylglucosaminidase in seminal plasma was observed with respect to those of men of normal fertility, but there were no differences when the results were expressed in $U$ per $10^{8}$ spermatozoa. In contrast, in varicocele patients with abnormal spermiograms there was a significant increase in the activities of $\beta$-glucuronidase, $\alpha$-mannosidase, $\beta$-galactosidase and $\beta$ - $N$-acetylglucosaminidase expressed in $U$ per $10^{8}$ spermatozoa compared with the fertile controls. Azoospermic patients showed significant decreases in the activities of all glycosidases analysed.

The results obtained in the soluble and non-soluble fractions of spermatozoa, expressed in $U$ per $10^{8}$ spermatozoa, are shown (Table 4). In comparison with the fertile controls, there was a significant increase in the activity of $\alpha$ mannosidase in the soluble fraction of spermatozoa from infertile varicocele subjects with abnormal spermiograms. There was a significant increase in the activities of $\beta$ - 
Table 2. Relationships between seminal parameters and glycosidase activities in seminal plasma and spermatozoa from fertile controls, infertile patients with varicocele and azoospermic men

\begin{tabular}{lcc}
\hline Glycosidase/seminal fraction & $R$ & $P$ value \\
\hline Relationships with number of spermatozoa & & \\
$\alpha$-mannosidase/seminal plasma $(n=71)$ & 0.235 & 0.04 \\
$\alpha$-glucosidase/seminal plasma $(n=65)$ & 0.401 & 0.0009 \\
$\alpha$-glucosidase/non-soluble fraction $(n=54)$ & 0.334 & 0.01 \\
$\alpha$-galactosidase/pellet wash $(n=52)$ & 0.363 & 0.008 \\
$\alpha$-galactosidase/soluble fraction $(n=54)$ & 0.412 & 0.001 \\
$\beta$-galactosidase/seminal plasma $(n=65)$ & 0.407 & 0.0007 \\
$\beta$-galactosidase/pellet wash $(n=52)$ & 0.561 & $<0.0001$ \\
$\beta$-galactosidase/soluble fraction $(n=54)$ & 0.395 & 0.003 \\
$\beta$-galactosidase/non-soluble fraction $(n=54)$ & 0.561 & 0.0001 \\
$\beta$-N-acetylglucosaminidase/seminal plasma $(n=61)$ & 0.380 & 0.002 \\
$\beta$ - $N$-acetylglucosaminidase/pellet wash $(n=51)$ & 0.276 & \\
& & 0.04 \\
Relationships with sperm motility (grade $3+2)$ & & 0.01 \\
$\beta$-glucuronidase/soluble fraction $(n=54)$ & 0.373 & 0.04 \\
$\alpha$-galactosidase/soluble fraction $(n=54)$ & 0.308 & 0.001 \\
$\beta$-galactosidase/soluble fraction $(n=54)$ & 0.473 & \\
\hline
\end{tabular}

Table 3. Acid glycosidase activities in seminal plasma from control fertile, varicocele and azoospermic men

\begin{tabular}{|c|c|c|c|c|}
\hline Acid glycosidase & Fertile controls & Varicocele (NS) & Varicocele (PS) & Azoospermic \\
\hline & $11.4 \pm 3.7(10.2)$ & $10.6 \pm 4.5(10.3)$ & $11.3 \pm 4.4(10.2)$ & $11.5 \pm 2.4(11.6)$ \\
\hline U per $10^{8}$ spermatozoa & $(11.9)$ & $(8.3)$ & $(17)^{*}$ & - \\
\hline$\alpha$-mannosidase $\mathrm{mU} \mathrm{ml}^{-1}$ & $19.3 \pm 17.6(15.9)$ & $25.0 \pm 10.8^{*}(21.3)^{*}$ & $21.6 \pm 7.7(23.7)$ & $15.2 \pm 6.3(13.2)$ \\
\hline U per $10^{8}$ spermatozoa & $(16.6)$ & $(16.6)$ & $(34.4)^{* *}$ & - \\
\hline$\alpha$-glucosidase $\mathrm{mU} \mathrm{m \textrm {m } ^ { - 1 }}$ & $13.0 \pm 7.6(12.4)$ & $16.6 \pm 7.3(14.9)$ & $12.8 \pm 8.5(9.4)$ & $7.0 \pm 5.9 *(4.9) *$ \\
\hline U per $10^{8}$ spermatozoa & $(12.1)$ & $(11.4)$ & $(14.4)$ & - \\
\hline$\alpha$-galactosidase $\mathrm{mU} \mathrm{ml}^{-1}$ & $0.4 \pm 0.4(0.2)$ & $0.8 \pm 1.1(0.3)$ & $0.4 \pm 0.4(0.3)$ & $0.4 \pm 0.9(0.1)$ \\
\hline U per $10^{8}$ spermatozoa & $(0.4)$ & $(0.3)$ & $(0.3)$ & - \\
\hline$\beta$-galactosidase $\mathrm{mU} \mathrm{ml}^{-1}$ & $0.7 \pm 0.5(0.6)$ & $1.2 \pm 0.7^{*}(1.1)^{*}$ & $0.7 \pm 0.3(0.5)$ & $0.4 \pm 0.3 *(0.4)^{*}$ \\
\hline U per $10^{8}$ spermatozoa & $(0.6)$ & $(0.7)$ & $(1.1)^{*}$ & - \\
\hline$\beta$ - $\mathrm{N}$-acetylglucosaminidase $\mathrm{mU} \mathrm{\textrm {ml } ^ { - 1 }}$ & $1844 \pm 792(1690)$ & $2573 \pm 954 *(2383)^{*}$ & $2524 \pm 1055(2374)$ & $1389 \pm 314 *(1384)^{*}$ \\
\hline U per $10^{8}$ spermatozoa & $(1787)$ & $(1753)$ & $(3344)^{* *}$ & - \\
\hline
\end{tabular}

Values in $\mathrm{mU} \mathrm{ml}^{-1}$ are expressed as means $\pm \mathrm{SD}$ and as medians (in parentheses). Results in $\mathrm{U}$ per $10^{8}$ spermatozoa are expressed as medians.

${ }^{*} P<0.05,{ }^{* *} P<0.01$ versus fertile controls.

NS: normal spermiogram; PS: pathological spermiogram.

galactosidase and $\beta$ - $N$-acetylglucosaminidase in the nonsoluble fraction of spermatozoa in infertile varicocele patients with normal spermiograms and in infertile varicocele patients with abnormal spermiograms, respectively.

\section{Discussion}

This study is the first to report abnormalities in the seminal content of $\alpha$-mannosidase, $\beta$-galactosidase and $\beta-N$ acetylglucosaminidase in infertile patients with varicocele. The abnormalities detected in the enzyme activities were consistent as the increases in activity were two- or threefold higher compared with those measured in men of normal fertility, because they were observed in both the extracellular and intracellular seminal fractions and because they involved the same glycosidase activities. Physicochemical solubilization of spermatozoa allows the extraction of the acrosome content (Skudlarek et al., 1993) in which sperm acid $\alpha$-glucosidase, $\alpha$-mannosidase and $\beta$-galactosidase activities are located (De Vries and Colenbrander, 1990). Therefore, the results from the present study indicate that infertile patients with varicocele and normal spermiograms overexpress acrosomal $\alpha$-mannosidase activity. Varicocele patients also overexpress $\beta$-galactosidase and $\beta$ - $N$-acetylglucosaminidase activities in the nonsoluble fraction of spermatozoa, which contains sperm membranes (Stambaugh and Buckley, 1969).

The possibility that the overexpression of $\alpha$-mannosidase, 
Table 4. Acid glycosidase activities ( $U$ per $10^{8}$ spermatozoa) in the soluble and non-soluble fractions of spermatozoa in control fertile and varicocele patients

\begin{tabular}{|c|c|c|c|}
\hline Acid glycosidase & Fertile controls & Varicocele (NS) & Varicocele (PS) \\
\hline \multicolumn{4}{|l|}{$\beta$-glucuronidase } \\
\hline Soluble & $0.05(0.0-0.4)$ & $0.04(0.0-0.5)$ & $0.01(0.0-2.5)$ \\
\hline Non-soluble & $0.09(0.0-2.7)$ & $0.14(0.0-1.2)$ & $0.01(0.0-2.5)$ \\
\hline \multicolumn{4}{|l|}{$\alpha$-mannosidase } \\
\hline Soluble & $0.23(0.0-6.5)$ & $0.57(0.1-2.2)$ & $1.30(0.3-7.4)^{* *}$ \\
\hline Non-soluble & $0.05(0.0-1.9)$ & $0.10(0.0-0.5)$ & $0.24(0.04-2.1)$ \\
\hline \multicolumn{4}{|l|}{$\alpha$-glucosidase } \\
\hline Soluble & $0.69(0.0-4.8)$ & $0.75(0.1-2.5)$ & $0.91(0.2-14.1)$ \\
\hline Non-soluble & $0.15(0.0-1.6)$ & $0.14(0.0-0.3)$ & $0.18(0.1-2.7)$ \\
\hline \multicolumn{4}{|l|}{$\alpha$-galactosidase } \\
\hline Soluble & $0.03(0.0-0.4)$ & $0.08(0.0-0.4)$ & $0.05(0.0-0.3)$ \\
\hline Non-soluble & $0.0(0.0-0.1)$ & $0.0(0.0-0.04)$ & $0.0(0.0-0.2)$ \\
\hline \multicolumn{4}{|l|}{$\beta$-galactosidase } \\
\hline Soluble & $0.05(0.0-0.5)$ & $0.09(0.0-0.3)$ & $0.03(0.0-1.4)$ \\
\hline Non-soluble & $0.12(0.0-1.2)$ & $0.28(0.04-0.5)^{*}$ & $0.16(0.02-1.2)$ \\
\hline \multicolumn{4}{|c|}{$\beta$ - $N$-acetylglucosaminidase } \\
\hline Soluble & $9.0(0.0-228.0)$ & $15.3(1.7-36.0)$ & $11.2(5.0-49.0)$ \\
\hline Non-soluble & $1.42(0.2-22.0)$ & $1.14(0.4-6.0)$ & $4.56(1.9-20.0)^{*}$ \\
\hline
\end{tabular}

$\beta$-galactosidase and $\beta$ - $N$-acetylglucosaminidase activities in spermatozoa represents contamination from bacterial cells, cytoplasmic droplets, immature germ cells or seminal tract cells is reduced by several observations. First, the intracellular activity of $\beta$-galactosidase was undetectable and activities of $\alpha$-mannosidase and $\beta$ - $N$-acetylglucosaminidase were negligible when spermatozoa were absent in azoospermic patients, the group considered as negative controls. Second, bacterial cultures were negative for all patients. Third, in the processing of spermatozoa, one of the steps consisted of washing spermatozoa in a medium with a salt content that was capable of removing the glycosidases adhering loosely to the sperm surface (Barbieri et al., 1994). Fourth, although it is possible that cytoplasmic droplets contribute to the glycosidase activities measured in the particulate fraction (Allison and Hartree, 1970), the contribution of these organelles to the activities measured in spermatozoa is negligible in comparison with the activities detected in sperm cells (Skudlarek et al., 1993; Tulsiani et al., 1993). The number of immature germ cells measured in all spermiograms was only 2-3 per 100 . However, the differences in the number of immature germs cells between the controls (median: 2) and normozoospermic varicocele patients (median: 2) as well as in varicocele patients with abnormal spermiograms (median: 2) were not recorded. However, it is noteworthy that acrosomes are found only on spermatids and spermatozoa (Tulsiani et al., 1998). Finally, contamination from seminal tract cells is unlikely, as in the patients with non-obstructive azoospermia the acid glyco- sidases content in the pellet was undetectable or negligible, as discussed above.

The increased expression of these glycosidases in spermatozoa could reflect a decrease in the maturation of spermatozoa in patients with varicocele, as immature spermatozoa also overexpress other enzymes, such as $\beta$ 1,4-galactosyltransferase in men (Huszar et al., 1997) or $\beta$ - $N$-acetylglucosaminidase in boars (De Vries and Colenbrander, 1990). Moreover, the sperm content of some glycosidases changes during the epididymal maturation of spermatozoa, showing a progressive decrease in the caudal portions as the spermatozoa mature (Hall and Killian, 1987). In male dogs suffering from fucosidosis, a hereditable lysosomal storage disorder, abnormal expression of another glycosidase ( $\alpha$-L-fucosidase) results in acrosomal dysgenesis and impaired sperm maturation, which could be related to the abnormal lysosomal content of hydrolases (Veeramachaneni et al., 1998). Since immature spermatozoa do not bind to the zona pellucida (Huszar et al., 1994), and as infertile patients with varicocele may show defective sperm binding, in which improvement by surgical repair correlates with fertility (Hauser et al., 1997), it is possible that the fertilizing capacity of spermatozoa in patients with varicocele is disminished as a result of abnormalities in the lysosomal content.

Chayko and Orgebin-Crist (2000) reported that homozygous mutant mice lacking the cation-dependent mannose 6-phosphate receptor overexpress the same acid glycosidase activities as detected in the varicocele patients in the 
present study, thus providing an alternative explanation for the results of the present study.

The varicocele patients with pathological spermiograms also showed an overexpression of $\alpha$-mannosidase, $\beta$-galactosidase and $\beta$ - $N$-acetylglucosaminidase $\left(U\right.$ per $10^{8}$ spermatozoa) activities in their seminal plasma. The significance of the high amounts of extracellular glycosidases usually present inside lysosomes (De Duve et al., 1955) or their physiological role is unknown. Extracellular glycosidases, such as $\beta$-galactosidase and fucosidase, play a role in the modification of sperm plasma membrane glycoproteins in rodents (Tulsiani et al., 1993, 1995). However, it is generally concluded that the sperm maturational process includes modifications of the carbohydrate content of sperm surface glycoproteins and that glycosidases may play a significant role in this event (Tulsiani et al., 1998). Moreover, ejaculated spermatozoa could be a target for glycosidases in the seminal plasma (Barbieri et al., 1996). It is therefore possible that such overexpression of acid glycosidase in the seminal plasma could mask the carbohydrate-containing molecules present in ejaculated spermatozoa, altering their fertilization potential, as fertilization is a carbohydratemediated event involving sperm surface glycoproteins (Tulsiani et al., 1997).

The possibility that the abnormal expression of acid glycosidases observed in the varicocele patients might be merely a consequence of damaged spermatozoa, irrespective of the cause, would be supported if the same results were observed in other infertile patients with abnormal spermiograms but without varicocele. However, in a study involving infertile patients with idiopathic oligoasthenoteratozoospermia, a different pattern in the enzyme activities was detected, characterized by significantly lower activities of $\beta$-galactosidase and $\beta$ - $N$-acetylglucosaminidase in the soluble fraction of spermatozoa compared with those in fertile controls (Corrales et al., 2000).

The occurrence of infertility in patients with varicocele, even though the seminal cytological parameters may be normal, raises the possibility that the spermatozoa of these patients could have functional defects. Some lines of evidence indicate that the glycosidases, the expression of which was found to be abnormal in the present study of infertile patients with varicocele, play a role in mammalian fertilization. Sugars that induce a dose-dependent inhibition of sperm $\alpha$-mannosidase activity produce a dose-dependent decrease in the number of spermatozoa bound per egg (Cornwall et al., 1991). Mori et al. (1989) showed that pretreatment of spermatozoa with D-mannose, a sugar that inhibits $\alpha$-mannosidase, blocks penetration of the zona pellucida by human spermatozoa. Sperm $\beta$-galactosidase and $\beta$ - $N$-acetylglucosaminidase activities change during epididymal transit, indicating that these enzymes play a significant role in the maturation of spermatozoa (Hall and Killian, 1987). Sperm acid $\beta$-galactosidase has been implicated in the modification of sperm surface glycoproteins (Tulsiani et al., 1995) as well as in the acrosome reaction (Nikolajczyk and O'Rand, 1992). Takada et al.
(1994) showed that inhibition of $\beta$ - $N$-acetylhexosaminidase reduces the in vitro fertilization rate in pig cumulusenclosed eggs. $\beta-N$-acetylglucosaminidase has been implicated in the penetration of the zona pellucida (Miller et al., 1993) and is considered to be the mediator that induces acrosome reaction in human spermatozoa (Brandelli et al., 1994).

Although the present study did not aim to analyse the function of these glycosidases in fertilization, the first criterion that a glycosidase must meet to play a role in fertilization is its presence in spermatozoa (Godknecht and Honegger, 1991). In the present study not only the presence of these enzymes but also an overexpression of several of the enzymes was detected. On theoretical grounds, it would be expected that if an enzyme performs a positive role in fertilization, then the higher the content of that enzyme the greater the function. However, it has been found that transgenic mice overexpressing sperm $\beta$-1,4-galactosyltransferase, another enzyme involved in gamete interactions (Miller et al., 1992), have a reduced ability to bind eggs and the spermatozoa that are able to bind to the zona pellucida are hypersensitive to ZP3, inducing a precocious acrosome reaction and unstable binding (Youakim et al., 1994). The sperm-egg interaction requires an optimal rather than maximal amount of $\beta-1,4-$ galactosyltransferase (Youakim et al., 1994), and this notion could also be true for glycosidases. Defective binding of human spermatozoa by the hemizone assay has been described in infertile patients with varicocele (Hauser et al., 1997).

In summary, if the glycosidase activities measured in fertile and normozoospermic controls are considered as representative of normality, then the expression of acid glycosidases in patients with varicocele is abnormal. This abnormality may be involved in impaired sperm function, which is considered as a pathogenic factor for infertility in patients with varicocele (Wong et al., 2000).

\section{References}

Allison AC and Hartree EF (1970) Lysosomal enzymes in the acrosome and their possible role in fertilization Journal of Reproduction and Fertility $\mathbf{2 1}$ 501-515

Barbieri MA, Sosa MA, Couso R, Ielpi L, Merello S, Tonn CE and Bertini F (1994) Affinity sites for $N$-acetyl- $\beta$-D-glucosaminidase on the surface of rat epididymal spermatozoa International Journal of Andrology 17 43-49

Barbieri MA, Veisaga ML, Paolicchi F, Fornes MW, Sosa MA, Mayorga LS, Bustos-Obregón E and Bertini F (1996) Affinity sites for $\beta$-glucuronidase on the surface of human spermatozoa Andrologia 28 327-333

Brandelli A, Miranda PV and Tezón JG (1994) Participation of glycosylated residues in the human sperm acrosome reaction: possible role of $\mathrm{N}$ acetylglucosaminidase Biochimica et Biophysica Acta 1220 299-304

Braunstein GD (1997) Testes. In Basic and Clinical Endocrinology pp 403-433 Eds FS Greenspan and G) Strewler. Appleton and Lange, London

Burgo R, Mories MT, Fraile A, Villar E, Miralles JM, García LC and Corrales J (2000) Análisis de las glicosidasas ácidas seminales como marcadores de la calidad seminal Endocrinología 47 Supplement 16

Chayko CA and Orgebin-Crist MC (2000) Targeted disruption of the cationdependent or cation-independent mannose 6-phosphate receptor does 
not decrease the content of acid glycosidases in the acrosome Journal of Andrology 21 944-953

Cooper TG, Yeung CH, Nashan D and Nieschlag E (1988) Epididymal markers in human infertility Journal of Andrology 9 91-101

Cornwall GA, Tulsiani DRP and Orgebin-Crist MC (1991) Inhibition of the mouse sperm surface $\alpha$-D-mannosidase inhibits sperm-egg binding in vitro. Biology of Reproduction 44 913-921

Corrales JJ, Miralles JM and García Díez LC (1990) Primary hypothyroidism and human spermatogenesis Archives of Andrology 25 21-27

Corrales JJ, Burgo RM, Miralles JM and Villar E (2000) Abnormalities in sperm acid glycosidases from infertile men with idiopathic oligoasthenoteratozoospermia Fertility and Sterility 73 470-478

De Duve C, Pressman BC, Gianetto R, Wattiaux R and Appelmans F (1955) Tissue fractionation studies. Intracellular distribution patterns of enzymes in rat-liver tissue Biochemical Journal 60 604-617

De Kretser DM and Baker HWG (1999) Infertility in men: recent advances and continuing controversies Journal of Clinical Endocrinology and Metabolism 84 3443-3450

De Vries ACJ and Colenbrander B (1990) Isolation and characterization of boar spermatozoa with and without a cytoplasmic droplet International Journal of Biochemistry 22 519-524

García Díez LC, González Buitrago JM, Corrales JJ, Battaner E and Miralles JM (1983) Hormone levels in serum and seminal plasma of men with different types of azoospermia Journal of Reproduction and Fertility $\mathbf{6 7}$ 209-214

García Díez LC, Corrales JJ, Hernández J, Pedraz MJ and Miralles JM (1991) Semen characteristics and diabetes mellitus. Significance of insulin in male infertility Archives of Andrology 26 119-128

Godknecht A and Honegger TG (1991) Isolation, characterization and localization of a sperm-bound $\mathrm{N}$-acetylglucosaminidase that is indispensable for fertilization in the Ascidian, Phallusia mammillata. Developmental Biology 143 398-407

Hall JC and Killian GJ (1987) Changes in rat sperm membrane glycosidase activities and carbohydrate and protein contents associated with epididymal transit Biology of Reproduction 36 709-718

Hauser R, Yogev L, Greif M, Hirshenbein A, Botchan A, Paz G, Gamzu R and Yavetz H (1997) Sperm binding and ultrasound changes after operative repair of varicocele: correlation with fecundity Andrologia 29 145-147

Huszar G, Vigue L and Oehninger S (1994) Creatine kinase immunocytochemistry of human hemizona-sperm complexes: selective binding of sperm with mature creatine kinase-staining pattern Fertility and Sterility 61 136-142

Huszar G, Sbracia M, Vigue L, Miller DJ and Shur BD (1997) Sperm plasma membrane remodeling during spermiogenetic maturation in men: relationship among plasma membrane $\beta$-1,4-galactosyltransferase, cytoplasmic creatine phosphokinase and creatine phosphokinase isoform ratios Biology of Reproduction 56 1020-1024

Lessley BA and Garner DL (1983) Distribution of Pz-peptidase in bovine epididymal and ejaculated semen Biology of Reproduction 28 447-459

Miller DJ, Macek MB and Shur BD (1992) Complementarity between sperm surface $\beta$-1,4-galactosyl-transferase and egg-coat ZP3 mediates spermegg binding Nature 357 589-593

Miller DJ, Gong X and Shur BD (1993) Sperm require $\beta-N$ acetylglucosaminidase to penetrate through the egg zona pellucida Development 118 1279-1289

Miralles JM, Corrales JJ, García Díez LC, Cabezas JA and Reglero A (1982) $N$-Acetyl $\beta$-D-glucosaminidase and $\alpha$-L-fucosidase activities in relation to glycosylated hemoglobin levels and to retinopathy in diabetes Clinica Chimica Acta 121 373-378

Mori K, Daitoh T, Irahara M, Kamada M and Aono T (1989) Significance of D-mannose as a sperm receptor site on the zona pellucida in human fertilization American Journal of Obstetrics and Gynecology 161 207-211

Nikolajczyk BS and O'Rand MG (1992) Characterization of rabbit testis $\beta$-galactosidase and arylsulfatase A: purification and localization in spermatozoa during acrosome reaction Biology of Reproduction $\mathbf{4 6}$ 366-378

Santiago L, Fraile A, Cordero M, Burgo R, Mories MT, Corrales JJ, García L, García C, Ortiz J and Miralles JM (1997) Estudio preliminar de 19 pacientes azoospérmicos mediante punción aspirativa con aguja fina (PAAF) testicular Endocrinología 44 Supplement 146

Schill WB, Topfer-Petersen E and Heissler E (1988) The sperm acrosome: functional and clinical aspects Human Reproduction 3 139-145

Skudlarek MD, Tulsiani DRP, Nagdas SK and Orgebin-Crist MC (1993) $\beta$-D-galactosidase of rat spermatozoa: subcellular distribution, substrate specificity and molecular changes during epididymal maturation Biology of Reproduction 49 204-213

Spiessens C, D'Hooghe T, Wouters E, Meuleman C and Vanderschueren D (1998) $\alpha$-Glycosidase activity in seminal plasma: predictive value for outcome in intrauterine insemination and in vitro fertilization Fertility and Sterility $\mathbf{6 9} 735-739$

Stambaugh R and Buckley J (1969) Identification and subcellular localization of the enzymes effecting penetration of the zona pellucida by rabbit spermatozoa Journal of Reproduction and Fertillity 19 423-432

Takada M, Yonezawa N, Yoshizawa M, Noguchi S, Hatanaka Y, Nagai T, Kikuchi K, Aoki H and Nakano M (1994) pH-sensitive dissociation and association of $\beta$ - $N$-acetylhexosaminidase from boar sperm acrosome Biology of Reproduction $\mathbf{5 0}$ 860-868

Tremblay RR, Chapdelaine P and Dubé JY (1982) Neutral $\alpha$-1,4-glucosidase in human seminal plasma: molecular forms in varicocele and after vasectomy Fertility and Sterility $\mathbf{3 8}$ 344-348

Tulsiani DRP, Skudlarek MD, Holland MK and Orgebin-Crist MC (1993) Glycosylation of rat sperm membrane during epididymal maturation Biology of Reproduction 48 417-428

Tulsiani DRP, Skudlarek MD, Araki Y and Orgebin-Crist MC (1995) Purification and characterization of two forms of $\beta$-D-galactosidase from rat epididymal luminal fluid: evidence for their role in the modification of sperm plasma membrane glycoprotein(s) Biochemical Journal 305 $41-50$

Tulsiani DRP, Yoshida-Komiya H and Araki Y (1997) Mammalian fertilization: a carbohydrate-mediated event Biology of Reproduction $\mathbf{5 7}$ $487-494$

Tulsiani DRP, Abou-Haila A, Loeser CR and Pereira BMJ (1998) The biological and functional significance of the sperm acrosome and acrosomal enzymes in mammalian fertilization Experimental Cell Research $240151-164$

Veeramachaneni DNR, Smith MO and Ellinwood NM (1998) Deficiency of fucosidase results in acrosomal dysgenesis and impaired sperm maturation Journal of Andrology 19 444-449

Warner TG and O'Brien JS (1979) Synthesis of 2-4-methyllumbelliferyl- $\alpha$ $\mathrm{D}-\mathrm{N}$-acetylneuraminic acid and detection of skin fibroblast neuraminidase in normal humans and sialidosis Biochemistry 18 2783-2797

Wong WY, Thomas CMG, Merkus JMWM, Zielhuis GA and SteegersTheunissen RPM (2000) Male factor subfertility: possible causes and the impact of nutritional factors Fertility and Sterility 73 435-442

World Health Organization (1999) Laboratory Manual for the Examination of Human Semen and Sperm-Cervical Mucus Interaction. 4th Edn. Cambridge University Press, Cambridge

Youakim A, Hathaway HJ, Miller DJ, Gong X and Shur BD (1994) Overexpressing sperm surface $\beta 1$,4-galactosyltransferase in transgenic mice affects multiple aspects of sperm-egg interactions Journal of Cell Biology 126 1573-1583

Manuscript received 6 July 2001.

First decision 25 July 2001.

Revised manuscript received 5 October 2001.

Accepted 25 October 2001. 